\title{
Smart Stethoscope Systems: A New Paradigm for Bedside Patient Monitoring \\ Mansy HA
}

Department of Mechanical and Aerospace Engineering, University of Central Florida, Orlando, USA

*Corresponding author: Mansy HA, Department of Mechanical and Aerospace Engineering, University of Central Florida, Orlando, USA, Tel: 407823 1655; E-mail: Hansen.Mansy@ucf.edu

Rec date: Apr 11, 2016; Acc date: Apr 26, 2016; Pub date: May 2, 2016

Copyright: ( 2016 Mansy HA. This is an open-access article distributed under the terms of the Creative Commons Attribution License, which permits unrestricted use, distribution, and reproduction in any medium, provided the original author and source are credited.

\begin{abstract}
Bedside monitoring of patients often involves measuring pulse, temperature, respiratory rate, and blood pressure. Auscultation can also provide useful diagnostic information but requires the presence of a healthcare provider and hence is done intermittently. New technologies of optimally designed sound acquisition and processing systems can make this adaptable for continuous patient monitoring. The state of the art as well as some of the features, advantages and challenges for using this technology for patient monitoring are discussed.
\end{abstract}

Keywords: Monitoring; Stethoscope; Auscultation

\section{Introduction}

\section{Current patient monitoring}

Bedside patient monitoring is an important part of the standard of care of hospitalized patients. Typical monitoring (in, e.g., operating rooms, intensive care units, emergency departments) usually involves measuring pulse, temperature, respiratory rate, and blood pressure and may also include pulse oximetry and spirometry [1]. Changes in these vital signs can be indicative of life-threatening conditions that may require urgent intervention or triage to intensified level of care. Patient monitoring in general wards, however, is usually intermittent and is often based on tradition [2]. Low frequency monitoring may not be optimal for the current hospital population, which tends to be older, more vulnerable, and having more complex procedures and possible higher rates of complications.

\section{Manual and automated auscultation}

Auscultation is a widely used procedure that provides useful diagnostic information, is readily available, is non-invasive and can be performed at a relatively low cost. The procedure is usually performed using a stethoscope that transmits sounds from the patient skin to the healthcare provider ear. Auscultation is typically performed by skilled personnel and is therefore, used intermittently for patient care. Early stethoscopes [3] were mechanical devices whose evolution has reached a plateau. These stethoscopes do not lend themselves to continuous monitoring because of their constant reliance on the human operator.

Electronic stethoscopes have also been developed and are typically based on transducers that convert sounds and vibrations at the skin surface into electrical signals. The transducers used vary in their principle of operation and may involve electret microphones, accelerometers, optical sensors, or piezoelectric films or discs. Electronic stethoscopes offer inherent flexibilities since their electrical output can be manipulated with relative ease. For example, filters and amplifier can be incorporated in the design of these stethoscopes to supplement the human hearing, which has frequency-dependent sensitivity and may not hear subtle sound changes. For example, the typical human hearing sensitivity drops by about 70 decibels at 20 Hertz $(\mathrm{Hz})$ compared to that at $1000 \mathrm{~Hz}$. As a result, some useful diagnostic information, especially at low frequencies may not be easily detectable by the unaided human ear. Most electronic stethoscopes are, however, expensive, non-disposable and, hence, require cleaning after each use to avoid cross contamination.

Advances in digital signal processing, artificial intelligence and the availability of electronic stethoscopes have increased interest in the development of systems that can automatically acquire and analyze biological sounds and vibrations and provide diagnostic information that may be used by healthcare providers and patients. Several studies have shown that computer assisted analysis was able to find correlations between acquired body sounds and certain pulmonary [4-12], gastrointestinal [13-18] or cardiovascular conditions [19-21].

Body sound acquisition and analysis systems can be designed for bedside patient monitoring in, for example, the emergency room, the intensive care unit, or operating room. Although these systems can provide useful diagnostic information to healthcare providers, they are often not utilized. This is likely due, at least in part, to the uncertainty of the benefit to the patient and the burden of having to attach the additional sensors and wires (i.e., in addition to the EKG electrodes and wires that are currently usually attached). To reduce this burden new optimally designed sensors should be designed and constructed. Desirable sensor characteristics include: high sensitivity and signal-tonoise ratio in the frequency range of interest, small size, low cost, easy attachment to the skin, disposability to avoid need for disinfection, and capability to integrate with EKG electrodes to reduce need for extra wires and reduce burden on the user.

The sensitivity and frequency response of most readily available stethoscopes is usually unknown, which makes it difficult to compare the results of different studies or chose optimal sensors for the sounds to be measured. Optimal sensors for different studies are expected to be different as acoustic energy may be concentrated in different frequency bands. For example while most of the heart sound energy is below $100 \mathrm{~Hz}$, breath sounds energy is more dominant between 100-1000 Hz. Testing of sensors is another important area of 
investigation and optimization. Special sensors testing phantoms are needed to properly document the frequency response and compare the performance of different stethoscopes. While there are no widely accepted methods for testing stethoscopes, there have been studies [22-26] that proposed certain phantom designs. Desired phantom characteristics include being made of materials that has density and elasticity similar to soft tissue, having high temporal stability, ready availability, low cost, and being made of materials that are easy to mold into desired shapes. The phantom also needs to be compact in size and able to supply surface acoustic signals that have high spectral and spatial uniformity, and able to test sensors of different sizes.

Computer simulations of acoustic phenomena in humans and animals have been also attempted [5,24,27-35]. The advantages of the in silico approach include its ability to quantify both surface and subsurface acoustic levels and predict acoustic values in areas where these are hard or not possible to measure. They may also be used in parametric studies that can elucidate the effects of the different parameters relatively quickly and economically. The resulting insights from these studies can help reduce the need for a large number of bench and animal studies needed for the development of new monitoring systems.

\section{References}

1. Morrell C, Micholson M, Hillman K (2015) Vital Signs: From Monitoring to preventions of deterioration in general wards. Annual update in ICU and Emergency Medicine 2015: 533-45.

2. Zeitz K, McCutcheon H (2006) Observations and vital signs: ritual or vital for the monitoring of postoperative patients? Appl Nurs Res 19: 204-211.

3. Roguin A (2006) Rene Theophile Hyacinthe Laennec (1781-1826): The man behind the stethoscope. Clinical Medicine and Research 4: 230-5.

4. Pasterkamp H, Kraman SS, Wodicka GR (1997) Respiratory sounds. Advances beyond the stethoscope. Am J Respir Crit Care Med 156: 974-987.

5. Mansy HA, Royston TJ, Sandler RH (2002) Use of abdominal percussion for pneumoperitoneum detection. Med Bio Eng 40: 439-46.

6. Mansy HA, Royston TJ, Balk RA, Sandler RH (2002) Detection of pneumothorax using computerized analysis of breath sounds. Med Bio Eng Comp 40: 526-32.

7. Mansy HA, Royston TJ, Balk RA, Sandler RH (2002) Detection of pneumothorax using pulmonary acoustic transmission measurements. Med Bio Eng Comp 40: 520-25.

8. Dellinger PR, Parrillo JE, Kushnir A, Rossi M, Kushnir I (2008) Dynamic visualization of lung sounds with a vibration response device: a case series. Respiration 75: 60-72.

9. O'Connor CJ, Mansy HA, Balk RA, Tauman KJ, Sandler RH (2005) Identification of endotracheal tube malpositions using computerized analysis of breath sounds via electronic stethoscopes. Anesthesia and Analgesia 101: 735-9.

10. Räsänen JO, Nemergut ME, Gavriely N (2014) Changes in breath sound power spectra during experimental oleic acid-induced lung injury in pigs. J Appl Physiol 116: 61-66.

11. Dai Z, Peng Y, Mansy HA, Sandler RH, Royston TR (2015) Experimental and computational studies of sound transmission in a branching airway network embedded in a compliant viscoelastic medium. Journal of Sound and Vibration 339: 215-29.

12. Mansy HA, Balk RA, Warren WH, Royston TJ, Dai Z, et al. (2015) Pneumothorax effects on pulmonary acoustic transmission. Journal of applied Physiology 119: 250-57.

13. Tomomasa T, Morikawa A, Sandler RH, Mansy HA, Masahiko T, et al. (1999) Gastrointestinal sounds and migrating motor complex in fasted humans. Am J Gastroenter 94: 374-81.
14. Mansy HA, Sandler RH (1997) Enhancement of bowel sounds by heart sound removal using adaptive filters. IEEE: Eng Med Biology Magazine 16: 105-17.

15. Mansy HA, Sandler RH (2000) Detection and analysis of gastrointestinal sounds in normal and small bowel obstruction rats. Med Biol Eng Comp 38: 42-48.

16. Mansy HA, Royston TJ, Sandler RH (2001) Acoustic characteristics of air cavities at low audible frequencies with application to pneumoperitoneum diagnosis. Med Bio Eng Comp 39: 159-68.

17. Royston TJ, Mansy HA, Sandler RH (2002) Modeling sound transmission through the pulmonary system and chest with application to diagnosis of a collapsed lung. J Acoustical Society of Am 111: 1931-46.

18. Kong X, Mansy HA, Sandler RH (2001) Multi resolution analysis of gastrointestinal sounds for small bowel obstruction identification. Int J Comp and App 8: 7-12.

19. Wang T, Tie B, Welkowitz W, Semmlow J, Kostis J (1990) Modeling sound generation in stenosed coronary arteries. IEEE Trans Biomed Eng 37: 1087-94.

20. Akay M, Akay Y, welkowitz W, Semmlow JL, Kostis JB (1992) Application of adaptive filters to noninvasive acoustical detection of coronary occlusions before and after angioplasty. IEEE Tans Biomed Eng 39: 176-183.

21. Mansy HA, Hoxie SJ, Patel NH, Sandler RH (2005) Computerized analysis of auscultory sounds associated with vascular patency of hemodialysis access. Med Biol Eng Comput 43: 56-62.

22. WatrousRL, Grove DM, Bowen DL (2002) Methods and results in characterizing electronic stethoscopes. Comput Cardiol 29: 653-6.

23. Zanartu M, Ho JC, Kraman SS, Pasterkamp H, Huber JE, et al. (2009) Airborne and tissue-borne sensitivities of bioacoustic sensors used on the skin surface. IEEE Trans Biomed Eng 56: 443-451.

24. Royston TJ, Mansy HA, Sandler RH (1999) Excitation and Propagation of Surface Waves on a Viscoelastic Half-Space with Application to Medical Diagnosis. J Acoustical Society of Am 106: 3678-86.

25. Mansy HA, Grahe JR, Sandler RH (2008) Elastic properties of synthetic materials for soft tissue modeling. Phys Med Biol 53: 2115-30.

26. Mansy HA, Grahe J, Royston TJ, Sandler RH (2011) Investigating a compact phantom and setup for testing body sound transducers. Comp Biol Med 41: 361-6.

27. Zhang X, Royston TJ, Mansy HA, Sandler RH (2001) Radiation impedance of a finite circular piston on a viscoelastic half-space with application to medical diagnosis. J Acoustical Soc Am 109: 795-802.

28. Acikgoz S, Ozer MB, Royston TJ, Mansy HA, Sandler RH (2009) Experimental and computational models for simulating sound propagation within the lungs. ASME J vibration and acoustics.

29. Dai Z, Peng Y, Mansy HA, Sandler RH, Royston TJ (2014) Comparison of poroviscoelastic models for sound and vibration in the lungs. ASME J Vib Acoust 136.

30. Dai Z, Peng Y, Henry B, Mansy HA, Sandler RH, et al. (2014) A Comprehensive computational model of sound transmission through the porcine lung. J Acous Soc Am 136: 1419-29.

31. Dai Z, Peng Y, Mansy HA, Sandler RH, Royston TR (2015) A Model of lung parenchyma stress relaxation using fractional viscoelasticity. Medical engineering \& physics 37: 752-758.

32. Peng Y, Dai Z, Mansy HA, Henry B, Sandler RH, et al. (2015) Sound transmission in porcine thorax through airway insonification. Medical \& Biological Engineering \& Computing 54: 675-89.

33. Peng Y, Dai Z, Mansy HA, Sandler RH, Balk RA, et al. (2014) Sound transmission in the chest under surface excitation: an experimental and computational study with diagnostic applications. Med Biol Engin Comput 52: 695-706.

34. Mansy HA, O'Connor CJ, Balk RA, Sandler RH (2005) Breath sound changes associated with malpositioned endotracheal tubes. Med Biol Eng Comput 43: 206-11. 
Citation: Mansy HA (2016) Smart Stethoscope Systems: A New Paradigm for Bedside Patient Monitoring. J Bioeng Biomed Sci 6: 187. doi: 10.4172/2155-9538.1000187

Page 3 of 3

35. Ozer MB, Acikgoz S, Royston TJ, Mansy HA, Sandler RH (2007)

Boundary element model for simulating sound propagation and source localization within the lungs. J Acoustical Soc Am 122: 657-61. 